\title{
Vitamin D Levels and Insulin Resistance in Children Born with Severe Growth Restriction
}

Authors

Affiliations

\section{I. Giapros ${ }^{1}$, A. S. Challa ${ }^{2}$, V. I. Cholevas ${ }^{2}$, E. N. Evagelidou ${ }^{1}$, E. T. Bairaktari ${ }^{3}$, S. K. Andronikou ${ }^{1}$}

${ }^{1}$ Neonatal Intensive Care Unit, University Hospital of Ioannina, loannina, Greece

${ }^{2}$ Pediatric Research Laboratory, Child Health Department, University of Ioannina, Ioannina, Greece

${ }^{3}$ Laboratory of Biochemistry, University of Ioannina, Ioannina, Greece
Key words

- vitamin D

- small-for-gestational-age

- insulin resistance

- $\beta$-cell function

- in utero growth restriction received 13.03.2012

accepted after second

revision 28.08.2012

Bibliography

DOI http://dx.doi.org/

10.1055/s-0032-1323815

Published online:

September 18, 2012

Horm Metab Res 2013;

45: 226-230

(c) Georg Thieme Verlag KG

Stuttgart · New York

ISSN 0018-5043

\section{Correspondence}

\section{I. Giapros}

University Hospital of Ioannina

P. O. Box 1186

45110 loannina

Greece

Tel.: + 30/2651/007544

Fax: + 30/2651/007 032

vgiapros@cc.uoi.gr

\section{Abstract}

$\nabla$

This study was designed to examine differences in serum 25(OH)D levels between small-for-gestational-age (SGA) and appropriate-for-gestational-age (AGA) prepubertal children in correlation with birth weight and indices of insulin resistance and $\beta$-cell function. Sixtyfive nonobese children were examined at age 5-7.5 years; 27 born SGA and 38 matched AGA. Body weight, height, BMI, and waist circumference were recorded and fasting serum levels of glucose, insulin, 25(OH)D, and parathyroid hormone (PTH) were measured. The homeostasis model assessment for insulin resistance (HOMAIR) and the $\beta$-cell function index (HOMA- $\beta \%$ ) were estimated. The mean level of $25(\mathrm{OH}) \mathrm{D}$ was

\section{Introduction}

$\nabla$

Recent studies have extended the activity of vitamin D [25(OH)D] well beyond that in calcium homeostasis and bone metabolism [1]. Clinical and experimental evidence supports a role of $25(\mathrm{OH}) \mathrm{D}$ in the pathogenesis of type 2 diabetes, with effects on either insulin sensitivity or $\beta$-cell function, or both [2,3]. Patients at risk for type 2 diabetes may have lower serum levels of $25(\mathrm{OH})$ D [3]. Positive correlation between levels of $25(\mathrm{OH}) \mathrm{D}$ and insulin sensitivity, and a negative effect of hypovitaminosis $D$ on $\beta$-cell function have also been observed in persons without glucose intolerance $[4,5]$.

Subjects born small-for-gestational age (SGA) because of intrauterine growth restriction constitute a population at risk of early development of chronic diseases, including type 2 diabetes [6]. A series of children born SGA had increased indices of insulin resistance early in life, correlated with both in utero growth restriction and accelerated postnatal growth [7-9]. 25(OH)D levels in higher in the SGA group ( $26.2 \pm 10$ vs. $17.2 \pm 7 \mathrm{ng} /$ $\mathrm{ml}, \mathrm{p}<0.01$ ) but that of PTH was no different. The insulin resistance and $\beta$-cell function indices were higher in the SGA group: HOMA-IR $1.34 \pm 0.67$ vs. $0.99 \pm 0.53$, and HOMA $-\beta \% 135 \pm 56$ vs. $97 \pm 60$ in the SGA and AGA groups, respectively. In the SGA group, 25(OH)D was correlated with HOMA- $\beta \%$ but not with HOMA-IR or insulin. In multiple regression, in the total cohort 25(OH)D and HOMA-IR were independently negatively correlated with birth weight $(\beta=-0.31$, $\beta=-0.36, p<0.05)$ respectively. In conclusion, at prepuberty severely in utero growth restricted children have increased birth weight dependent levels of $25(\mathrm{OH}) \mathrm{D}$, which might exert a regulatory role on $\beta$-cell function.

correlation to insulin resistance have not been studied in this population. This case-control study was designed to investigate the relationships between serum levels of vitamin 25(OH)D, indices of insulin resistance and $\beta$-cell function, and birth weight in prepubertal children with severe in utero growth restriction.

\section{Research Design and Methods}

$\nabla$

The study aimed to include all children born SGA at the University Hospital of Ioannina after a term pregnancy (GA 37-41 weeks) during the 18-month period January 2003-June 2004. Most of the births ( $>80 \%$ ) in a well-defined area of northwest Greece took place in this hospital. SGA children were defined as having birth weight $<2$ standard deviations (SDs) below the mean based on local growth charts. Of the children born SGA during the 18-month period, 44 were eligible; for 27 (15 males) of which the parents gave consent for participation in the study. Of the other chil- 
dren, the parents of 12 did not wish their children to participate and for 5 the contact details were not found. The clinical and socio-economic characteristics of the nonparticipating children did not differ from those of the study group.

The control group comprised 38 children (19 males) born in the hospital during the same period, appropriate for gestational age (AGA), defined as having birth weight between the $20^{\text {th }}$ and $80^{\text {th }}$ percentiles for gestational age on local growth charts specific for age and gender. They were matched with the SGA children for age, gender, height, weight, body mass index (BMI), and pubertal status (stage 1 according to the Tanner criteria for puberty development). A total of 170 AGA children were initially contacted to indentify the 38 matched controls. All the study children were healthy, were not receiving drugs for any cause, and had no history of liver or renal disease or malabsorption. Exclusion criteria for both groups were: congenital malformations or genetic disorders, known metabolic disorder or chronic disease, obesity (BMI $\geq 95$ ) at the time of the study, and a positive family history of diabetes or gestational diabetes.

The study protocol was approved by the Research Ethics Committee of Ioannina University Hospital. The parents of the eligible children were contacted, their written informed consent was secured and the children were evaluated at between 5 and 7.5 years of age. The following anthropometric data were recorded: birth weight, crown to heel length, and head circumference, obtained from the birth records, and body weight, body height, BMI and waist circumference at the time of the study, measured by standard methods. z-Scores for birth weight, BMI and waist circumference were derived from appropriate reference population standards. A morning venous blood sample for biochemical determinations was collected from each child after a rigorous $12 \mathrm{~h}$ fast, during the winter months (December-February); recruitment was balanced between SGA and AGA children across the months.

Fasting serum levels of glucose, insulin $25(\mathrm{OH}) \mathrm{D}$, and parathyroid hormone (PTH) were measured. Insulin was determined using an immunoenzymatic method (analyzer AXSYM, Abbott) and glucose by the glucose oxidase method. The homeostasis model assessment for insulin resistance (HOMA-IR) index and $\beta$-cell function (HOMA- $\beta \%$ ) was used to detect the degree of insulin resistance and $\beta$-cell function, respectively [10]. HOMAIR was assessed by the formula: [(insulin $(\mathrm{mU} / \mathrm{l}) \times$ glucose $(\mathrm{mmol} / \mathrm{I})] / 22.5$, and HOMA- $\beta \%$ by $[20 \times$ insulin $(\mathrm{mU} / \mathrm{l}) /$ (glucose ( $\mathrm{mmol} / \mathrm{l})-3.5]$.

25(OH)D was determined by an enzyme-immunoassay (EIA) method using the kit of IDS Systems Ltd, UK. The sensitivity of the method was $5.0 \mathrm{nmol} / \mathrm{l}$, and the intra- and interassay CVs were $5.3 \%$ and $4.6 \%$, respectively. The biologically intact molecule of PTH (iPTH) was measured by a 2-site enzyme linked immunosorbent assay (ELISA) using the kit of BIOMERICA Inc. (USA). The sensitivity of the method was $0.09 \mathrm{pmol} / \mathrm{l}$, and the intra- and interassay CVs were $3.2 \%$ and $7.7 \%$, respectively. The sample volume required for each assay was $25 \mu l$. A detailed questionnaire was completed by the parents of each child at the time of the study, concerning outdoor activities and food consumption, with emphasis on oral vitamin D preparations and foods containing or enriched with vitamin D (i.e., oily fish, eggs, and fortified breakfast cereals). Dietary vitamin D intake was estimated, based on the USDA food composition data (http:// www.ars.usda.gov/nutrientdata), and on the labels in the case of the fortified breakfast cereals.

\section{Statistical analysis}

Students' $t$-test was used after examination of parameters for normal distribution. Simple and multiple regression analyses were conducted to define relationships among the examined parameters, namely $25(\mathrm{OH}) \mathrm{D}$ level, birth weight z-scores, insulin resistance and $\beta$-cell function indices, BMI, waist circumference $z$-scores and age. A sample size of 65 children could define a $25 \%$ difference among parameters with a power of $80 \%$ at the $p<0.05$ level [11]. Statistical analyses were performed using the Stat View software package of SAS Institute Inc. (Cary, USA).

\section{Results}

According to the questionnaire data, the AGA and SGA children showed no differences in their diet (caloric content, food type, etc.) or time spent on outdoor activity. The mean dietary vitamin $D$ intake estimated on a weekly basis was no different between the 2 groups: $990 \pm 250$ (SGA) and $950 \pm 235$ (AGA) IU/week.

As shown in $\odot$ Table 1, the mean serum level of 25(OH)D was higher in the SGA group. In 2 SGA and 20 AGA children, the level of $25(\mathrm{OH}) \mathrm{D}$ was below a cutoff value of $15 \mathrm{ng} / \mathrm{ml}$, while in 3 of the AGA children it was below $10 \mathrm{ng} / \mathrm{ml}$. Only 6 SGA and 2 AGA children had 25(OH)D levels above $30 \mathrm{ng} / \mathrm{ml}$, which has recently been proposed as the cutoff of adequacy.

The insulin resistance indices for fasting insulin and HOMA-IR were higher in the SGA group, while HOMA- $\beta \%$, which represents $\beta$-cell function, was favorable in this group. PTH level did not differ between the 2 groups. By comparing children with $25(\mathrm{OH}) \mathrm{D}$ levels below and above $15 \mathrm{ng} / \mathrm{ml}$ no differences in insulin resistance and $\beta$-cell function indices were found (data not shown).

In simple regression analysis in the SGA group, the 25-OH D level was positively correlated with HOMA- $\beta \%(R=0.38, p<0.05$, - Fig. 1), but not with HOMA-IR or fasting insulin ( $R=0.16,0.14$, respectively, $\mathrm{p}=\mathrm{ns}$ ). In the AGA group $25-\mathrm{OH} \mathrm{D}$ was not correlated with either HOMA- $\beta \%$ or HOMA-IR or insulin or $(\mathrm{R}=0.17$, $-0.08,-0.07$, respectively). PTH showed no correlation with vthe metabolic indices in any group or the total cohort.

Table 1 Anthropometric characteristics and metabolic variables in prepubertal children, born small (SGA) or appropriate (AGA) for gestational age.

\begin{tabular}{|c|c|c|}
\hline & SGA $(n=27)$ & AGA $(n=38)$ \\
\hline \multicolumn{3}{|l|}{ At birth } \\
\hline Gestational age (weeks) & $38.4 \pm 1.3$ & $38.3 \pm 1.3$ \\
\hline Birth weight $(\mathrm{g})$ & $1894 \pm 440^{* * *}$ & $3338 \pm 390$ \\
\hline Birth weight $(\mathrm{g})$ z-score & $-3.42 \pm 92^{* * *}$ & $-0.13 \pm 0.98$ \\
\hline Birth length $(\mathrm{cm})$ & $45.1 \pm 3.7^{* *}$ & $51.3 \pm 2.6$ \\
\hline \multicolumn{3}{|l|}{ At the time of study } \\
\hline Age (years) & $5.9 \pm 1.6$ & $6.2 \pm 1.1$ \\
\hline Body weight (kg) & $25.2 \pm 7.1$ & $26.7 \pm 6.1$ \\
\hline Body height $(\mathrm{cm})$ & $119 \pm 9$ & $120.8 \pm 9$ \\
\hline $\operatorname{BMI}\left(\mathrm{kg} / \mathrm{m}^{2}\right)$ & $17.4 \pm 3.1$ & $17.8 \pm 2.1$ \\
\hline BMI-SDS & $-0.08 \pm 1.0$ & $0.29 \pm 0.7$ \\
\hline Waist circumference-SDS & $0.04 \pm 1.2$ & $0.53 \pm 1.2$ \\
\hline 25(OH)D (ng/ml) & $26.2 \pm 10^{* * *}$ & $17.2 \pm 7$ \\
\hline iPTH (pg/ml) & $21.8 \pm 14$ & $23.2 \pm 9.2$ \\
\hline Fasting glucose (mg/dl) & $80.2 \pm 9.2$ & $82.3 \pm 6.5$ \\
\hline Fasting insulin $(\mu \mathrm{lU} / \mathrm{ml})$ & $6.35 \pm 3.4^{*}$ & $4.62 \pm 2.21$ \\
\hline HOMA-IR & $1.34 \pm 0.67^{*}$ & $0.99 \pm 0.53$ \\
\hline HOMA- $\beta \%$ & $135 \pm 56^{*}$ & $97.0 \pm 60$ \\
\hline
\end{tabular}




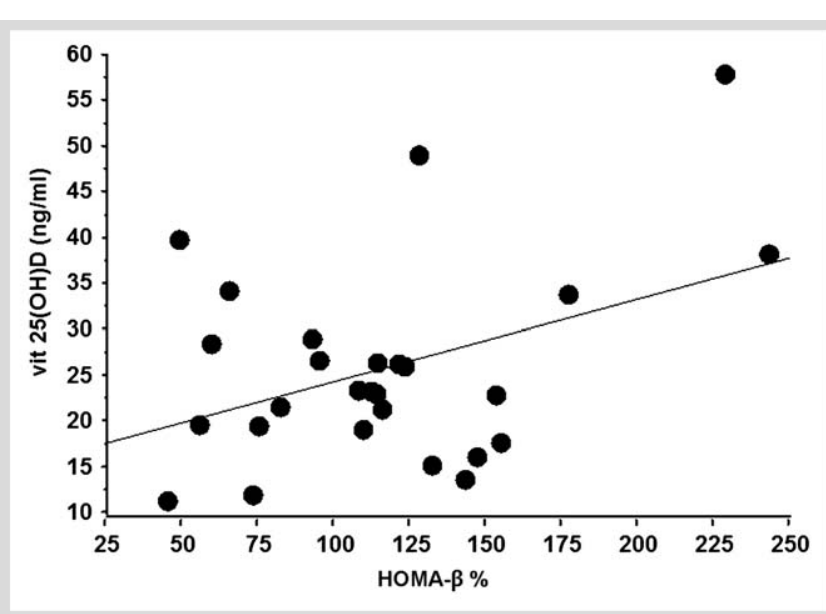

Fig. 1 Relationship between serum $25(\mathrm{OH}) \mathrm{D}$ level and $\mathrm{HOMA}-\beta \%$ in the small for gestational age (SGA) children of the study $(n=27)$.

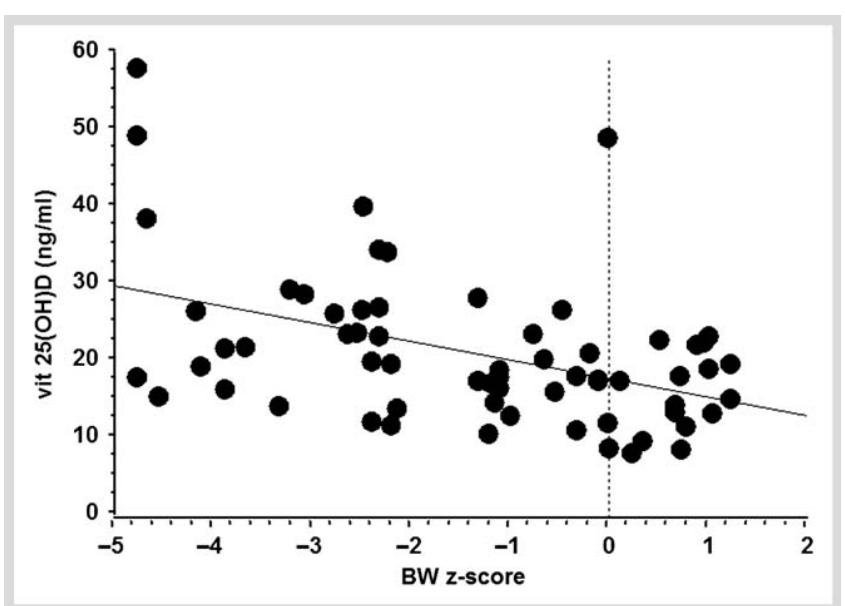

Fig. 2 Relationship between serum 25(OH)D level and birth weight (BW) $z$-scores in the study children $(n=65)$.

Multiple regression analysis was conducted for the total cohort of children to identify possible relationships between the birth weight z-score (dependent variable) and $25(\mathrm{OH}) \mathrm{D}$ levels, insulin resistance indices, and obesity indices after appropriate adjustments. The birth weight $z$-score, was negatively associated with $25(\mathrm{OH}) \mathrm{D}(\beta=-0.31, \mathrm{p}=0.02)$ after adjusting for waist circumference, BMI, HOMA-IR, and age ( $\odot$ Fig. 2 ). The birth weight z-score was negatively associated with HOMA-IR $(\beta=-0.36, p=0.003)$ after adjusting for BMI, waist circumference z-scores, 25(OH)D, and age. This relationship was stronger without $25(\mathrm{OH}) \mathrm{D}$ in the model $(\beta=-0.39, p<0.0004)$ but continued to be strong after entering $25(\mathrm{OH}) \mathrm{D}$. Finally the birth weight $z$-score was positively associated with waist circumference $z$-score $(\beta=+0.28$ $\mathrm{p}=0.03$ ) after adjusting for HOMA-IR, insulin, $25(\mathrm{OH}) \mathrm{D}$, and age.

\section{Discussion}

$\nabla$

This study showed that children born severely SGA had higher levels of 25(OH)D than those of AGA in prepuberty, affected indices of insulin resistance (insulin and HOMA-IR) in accordance with the findings of other researchers [7-9] but improved insulin secretion (HOMA- $\beta \%$ ). No correlation between $25(\mathrm{OH}) \mathrm{D}$ and insulin resistance was found but a positive relationship between $25(\mathrm{OH}) \mathrm{D}$ and HOMA- $\beta$ \% was demonstrated in the SGA group.

Studies conducted mainly in adults have shown inverse relationships between 25(OH)D levels and indices of insulin resistance or risk of type 2 diabetes or several other components of the metabolic syndrome and positive relationships between $25(\mathrm{OH})$ $D$ levels and $\beta$-cell function [4,5,12-14], although these findings were not confirmed in some reports [15]. Conversely, in agreement with the present study, several studies in children have failed to show association between vitamin $\mathrm{D}$ and insulin resistance [16-20]. Even in studies in children where correlation between vitamin $\mathrm{D}$ and several components of the metabolic syndrome was found, independent relationships between insulin resistance indices and 25(OH)D were not confirmed [21-23]. Pacifico et al. [23] found that after making appropriate adjustments (including BMI) only blood pressure and the metabolic syndrome remained significantly correlated with vitamin $D$, but not with IR indices (insulin or HOMA). Similarly, Gannagé-Yared et al. [22] showed that vitamin D was an independent predictor of systolic blood pressure and fasting glucose, but not of insulin or HOMA-IR.

It could be speculated that at this early period of life other factors may influence vitamin $\mathrm{D}$ and insulin resistance. One such factor could be PTH, as vitamin D deficiency results in hyperparathyroidism [24,25], through which glucose metabolism may be affected. Higher PTH, but not lower vitamin D, was shown to increase the risk of metabolic syndrome in a recent study [26]. In the present study PTH levels were similar in the 2 groups, implying that the observed difference in vitamin $\mathrm{D}$ may not be sufficient to affect the PTH level. Furthermore, no clear association between PTH level and insulin resistance indices was found.

Another explanation is that the levels of vitamin D, although higher in the SGA group, were below the recently proposed insufficiency threshold ( $32 \mathrm{ng} / \mathrm{ml}$ ), thus lacking a favorable effect on the insulin resistance, which could possibly confer a higher 25(OH)D serum level. A Canadian study in children showed that even a high increment in 25(OH)D level (i.e., $10 \mathrm{ng} / \mathrm{ml}$ ) correlated with only a slight decrease in the fasting blood glucose level and HOMA- IR [18]. There is also some evidence for a lower threshold by which vitamin $\mathrm{D}$ deficiency confers negative effects on insulin sensitivity [27]. In a previous study in adolescents, this threshold was estimated at $15 \mathrm{ng} / \mathrm{ml}$ [27], but application of this threshold to the present study generated no differences in insulin resistance indices.

Other studies have demonstrated correlation of high 25(OH)D levels with $\beta$-cell function rather than insulin resistance [28]. This was the case in the present study in SGA group where the higher, positively correlated with $25(\mathrm{OH}) \mathrm{D}$, HOMA- $\beta \%$ imply increased $\beta$-cell function. The higher HOMA- $\beta \%$ may attenuate the risk for impaired glucose tolerance posed by the higher HOMA-IR in this group, as the risk of the 2 parameters is regarded as additive [29].

The higher vitamin D levels in SGA children are difficult to interpret, but they could be related to differences in adipose tissue between the 2 groups. Although the groups were matched for BMI, waist circumference was about $0.5 \mathrm{z}$-score higher in AGA group. This difference, although not statistically significant may be physiologically significant with regard to vitamin D serum level. Higher adiposity values would provide a larger distribution volume and lower circulating 25(OH)D in the AGA group. Higher 25(OH)D level was shown to be independently correlated with low birth-weight in the present study. This relationship 
may arise from alterations in adipose tissue due to in utero growth restriction. It has been demonstrated that SGA children have a diminished capacity to store fat subcutaneously (the metabolic equivalent of a partial lipodystrophy) [30], thus the SGA children in this study may have had a limited overall storage capacity for vitamin $\mathrm{D}$, with the result that higher circulating vitamin D levels were measured. This hypothesis, however, is difficult to prove, as fat partitioning and tissue vitamin D were not studied in the present study.

Catch-up growth occurs in over $90 \%$ of SGA children. This was the case for the SGA study children, who were all within the normal range of development at prepuberty, and around the mean, despite their severe growth restriction at birth. The increased insulin resistance indices may therefore be related with both their low birth-weight and subsequent accelerated growth $[7,8]$. Obese children were excluded from the present study to avoid the well documented effect of adiposity on both 25(OH)D level and insulin resistance status, thus the results of the present study are limited in nonobese SGA children who had experienced catch-up growth.

Other limitations of this study are the small sample size and the use of surrogates of glucose homeostasis, although they correlate well with standard methods $[10,31]$. The small number of included children could lead to sample bias limiting the possibilities of finding other associations beyond those already indentified. Moreover possible selection bias could not be excluded since the final number of included SGA children was considerably smaller than the original target population. The duration of sunshine exposure was based on parental recall, so slight differences in time spent outdoors could confound the estimations of vitamin D status. The differences in $25(\mathrm{OH}) \mathrm{D}$ levels were too large, however, to be attributed to slight deviations in sun-exposure time between the 2 groups belonging to the same cohort and living in the same geographical area (latitude $39^{\circ} \mathrm{N}$ ). Finally, as the study was observational, the alterations found in the parameters measured may be physiologically unrelated or due to other unrecognized factors.

To the best of authors' knowledge, this is the first study to examine $25(\mathrm{OH}) \mathrm{D}$ in a special population with severe in utero growth restriction and a tendency to become insulin resistant early in life. Nonobese SGA born children had higher serum 25(OH)D levels, which were correlated with insulin secretion, but not with insulin resistance indices. Low birth weight appears to be a factor that is correlated independently with both 25(OH)D levels and insulin resistance in this group of children.

\section{Acknowledgements \\ $\nabla$}

We thank Aphroditi Papagianni of the Pediatric Research laboratory for her technical assistance.

\section{Conflict of Interest \\ $\nabla$}

The authors have no conflict of interest. There was no funding/ financial support for this study.

\section{References}

1 Holick MF. Vitamin D: importance in the prevention of cancers, type 1 diabetes, heart disease, and osteoporosis. Am J Clin Nutr 2004; 79: $362-371$

2 Teegarden D, Donkin SS. Vitamin D: emerging new roles in insulin sensitivity. Nutr Res Rev 2009; 22: 82-92

3 Boucher BJ, Mannan N, Noonan K, Hales CN, Evans SJ. Glucose intolerance and impairment of insulin secretion in relation to vitamin D deficiency in east London Asians. Diabetologia 1995; 38: 1239-1245

4 Chiu KC, Chu A, Go VL, Saad MF. Hypovitaminosis D is associated with insulin resistance and beta cell dysfunction. Am J Clin Nutr 2004; 79: 820-825

5 Liu E, Meigs JB, Pittas AG, McKeown NM, Economos CD, Booth SL, Jacques $P F$. Plasma 25-hydroxyvitamin $\mathrm{d}$ is associated with markers of the insulin resistant phenotype in nondiabetic adults. J Nutr 2009; 139: 329-334

6 Barker DJ, Hales CN, Fall CH, Osmond C, Phipps K, Clark PM. Type 2 (non-insulin-dependent) diabetes mellitus, hypertension and hyperlipidaemia (syndrome X): relation to reduced fetal growth. Diabetologia 1993; 36: 62-67

7 Mericq V, Ong KK, Bazaes R, Peña V, Avila A, Salazar T, Soto N, Iñiguez $G$, Dunger $D B$. Longitudinal changes in insulin sensitivity and secretion from birth to age three years in small- and appropriate-for-gestational-age children. Diabetologia 2005; 48: 2609-2614

8 Ong KK, Petry CJ, Emmett PM, Sandhu MS, Kiess W, Hales CN, Ness AR, Dunger DB; ALSPAC study team. Insulin sensitivity and secretion in normal children related to size at birth, postnatal growth, and plasma insulin-like growth factor-I levels. Diabetologia 2004; 47: 1064-1070

9 Giapros V, Andronikou S. Serum Adiponectin Levels, Insulin Resistance, and Lipids in Catch-Up and No Catch-Up Growth. In Preedy VR (ed.). Handbook of Growth and Growth Monitoring in Health and Disease. New York: Springer, 2012; 987-1005

10 Wallace TM, Levy JC, Matthews DR. Use and abuse of HOMA modeling. Diabetes Care 2004; 27: 1487-1495

11 Altman D. Practical Statistics for Medical Research. London: Chapman and Hall, 1991; 456-460

12 Kayaniyil S, Vieth $R$, Harris SB, Retnakaran R, Knight JA, Gerstein HC, Perkins BA, Zinman B, Hanley AJ. Association of $25(\mathrm{OH}) \mathrm{D}$ and PTH with metabolic syndrome and its traditional and nontraditional components. J Clin Endocrinol Metab 2011; 96: 168-175

13 Olson ML, Maalouf NM, Oden JD, White PC, Hutchison MR. Vitamin d deficiency in obese children and its relationship to glucose homeostasis. J Clin Endocrinol Metab 2012; 97: 279-285

14 Devaraj S, Jialal G, Cook T, Siegel D, Jialal I. Low vitamin D levels in Northern American adults with the metabolic syndrome. Horm Metab Res 2011; 43: 72-74

15 Del Gobbo LC, Song Y, Dannenbaum DA, Dewailly E, Egeland GM. Serum 25-hydroxyvitamin $D$ is not associated with insulin resistance or beta cell function in Canadian Cree. J Nutr 2011; 141: 290-295

16 Reinehr T, de Sousa G, Alexy U, Kersting M, Andler W. Vitamin D status and parathyroid hormone in obese children before and after weight loss. Eur J Endocrinol 2007; 157: 225-232

17 Erdönmez D, Hatun S, Çizmecioğlu FM, Keser A. No relationship between vitamin D status and insulin resistance in a group of high school students. J Clin Res Pediatr Endocrinol 2011; 3: 198-201

18 Delvin EE, Lambert M, Levy E, O'Loughlin J, Mark S, Gray-Donald K, Paradis $G$. Vitamin D status is modestly associated with glycemia and indicators of lipid metabolism in French-Canadian children and adolescents. J Nutr 2010; 140: 987-991

19 Lenders CM, Feldman HA, Von Scheven E, Merewood A, Sweeney C, Wilson DM, Lee PD, Abrams SH, Gitelman SE, Wertz MS, Klish WJ, Taylor GA, Chen TC, Holick MF; Elizabeth Glaser Pediatric Research Network Obesity Study Group. Relation of body fat indexes to vitamin D status and deficiency among obese adolescents. Am J Clin Nutr 2009; 90: 459-467

20 Rajakumar K, de las Heras J, Lee S, Holick MF, Arslanian SA. 25-hydroxyvitamin $\mathrm{D}$ concentrations and in vivo insulin sensitivity and $\beta$-cell function relative to insulin sensitivity in black and white youth. Diabetes Care 2012; 35: 627-633

21 Smotkin-Tangorra M, Purushothaman R, Gupta A, Nejati G, Anhalt H, Ten S. Prevalence of vitamin D insufficiency in obese children and adolescents. J Pediatr Endocrinol Metab 2007; 20: 817-823

22 Gannagé-Yared MH, Chedid R, Khalife S, Azzi E, Zoghbi F, Halaby G. Vitamin $D$ in relation to metabolic risk factors, insulin sensitivity and adiponectin in a young Middle-Eastern population. Eur J Endocrinol 2009; 160: 965-971 
23 Pacifico L, Anania C, Osborn JF, Ferraro F, Bonci E, Olivero E, Chiesa C. Low 25(OH)D3 levels are associated with total adiposity, metabolic syndrome, and hypertension in Caucasian children and adolescents. Eur J Endocrinol 2011; 165: 603-611

24 Zitterman A. Vitamin D in preventive medicine: are we ignoring the evidence? Br J Nutr 2003; 89: 552-572

25 Vieth R. Vitamin D supplementation, 25- hyrdoxyvitamin D concentrations and safety. Am J Clin Nutr 1999; 69: 842-856

26 Soares MJ, Ping-Delfos WC, Sherriff JL, Nezhad DH, Cummings NK, Zhao $Y$. Vitamin D and parathyroid hormone in insulin resistance of abdominal obesity: cause or effect? Eur J Clin Nutr 2011; 65: 1348-1352

27 Ashraf A, Alvarez J, Saenz K, Gower B, McCormick K, Franklin F. Threshold for effects of vitamin D deficiency on glucose metabolism in obese female African-American adolescents. J Clin Endocrinol Metab 2009; 94: 3200-3206

28 Kayaniyil S, Retnakaran R, Harris SB, Vieth R, Knight JA, Gerstein HC, Perkins BA, Zinman B, Hanley AJ. Prospective associations of vitamin $D$ with $\beta$-cell function and glycemia: the PROspective Metabolism and ISlet cell Evaluation (PROMISE) cohort study. Diabetes 2011; 60: $2947-2953$
29 Song Y, Manson JE, Tinker L, Howard BV, Kuller LH, Nathan L, Rifai N, Liu S. Insulin sensitivity and insulin secretion determined by homeostasis model assessment and risk of diabetes in a multiethnic cohort of women: the Women's Health Initiative Observational Study. Diabetes Care 2007; 30: 1747-1752

30 Ibáñez L, Lopez-Bermejo A, Díaz M, Suárez L, de Zegher F. Low-Birth Weight Children Develop Lower Sex Hormone Binding Globulin and Higher Dehydroepiandrosterone Sulfate Levels and Aggravate their Visceral Adiposity and Hypoadiponectinemia between Six and Eight Years of Age. J Clin Endocrinol Metab 2009; 94: 3696-3699

31 Bonora E, Targher G, Alberiche M, Bonadonna RC, Saggiani F, Zenere MB, Monauni T, Muggeo M. Homeostasis model assessment closely mirrors the glucose clamp technique in the assessment of insulin sensitivity: studies in subjects with various degrees of glucose tolerance and insulin sensitivity. Diabetes Care 2000; 23: 57-63 